\title{
A decision support tool for assessing risks to above-ground river pipeline crossings
}

Georgios Maniatis DipEng, MSc, PhD

Lecturer, School of Environment and Technology, University of Brighton, England, UK; Honorary Researcher, School of Geographical and Earth Sciences, University of Glasgow, Glasgow, UK (Orcid:0000-0001-7774-9499)

Richard D. Williams MA, MRes, PhD, MCIWEM, CSci, CEnv CWEM, FHEA

Senior Lecturer, School of Geographical and Earth Sciences, University of Glasgow, Glasgow, UK (corresponding author: richard.williams@glasgow.ac.uk) (Orcid:0000-0001-6067-1947)
Trevor B. Hoey MA, PhD

Professor, School of Geographical and Earth Sciences, University of Glasgow, Glasgow, UK (Orcid:0000-0003-0734-6218)

John Hicks BSC, CEng, MICE

Senior Engineer, Strategic Planner, Inspection and Testing, Scottish Water, Dunfermline, UK

William Carroll MA, MEng

Technical Lead (Resilience), Scottish Water, Dunfermline, UK

Infrastructure assets require suitable management and assessment protocols due to age-related deterioration, extreme weather events and climate change impacts. Above-ground river crossings are weak links in pipe networks since bank erosion and scour can undermine the integrity of built structures. A simple protocol was developed to assess river bank stability in the vicinity of river pipeline crossings. The erosion risk index (ERI) follows established bank erosion estimation techniques, adapted for users who are not trained geomorphologists. Calculation of the ERI is based on analysis of photographs acquired during an optimised inspection protocol using a custom app on a ruggedised tablet computer. The ERI was tested across Scotland and proved to be adequate for a first-order geomorphological assessment and to provide a classification of crossings according to susceptibility to river bank erosion. The ERI is transferable, with appropriate testing, to other infrastructure river crossing networks in the UK and beyond. The methodology used to develop and test the ERI is applicable to the development of other protocols to manage and assess infrastructure assets.

\section{Introduction}

Managers of infrastructure assets require databases that include high-quality asset data and associated analytical tools to provide evidence for making operational and investment decisions. Such data are becoming increasingly important because ageing infrastructure systems (Hall et al., 2014) must be managed, made resilient to extreme weather events and adapted to mitigate climate change impacts (Arnell et al., 2015; Garnaut, 2008; Thompson et al., 2017). National assessments of ageing infrastructure have been undertaken in countries including Australia (Sonnenberg, 2012), Canada (Gaudreault and Lemire, 2006) and New Zealand (Coleman and Melville, 2001). In the UK, the resilience of critical infrastructure to extreme weather events has been analysed extensively (Hall et al., 2016) and is recognised as a problem with important social implications (Cabinet Office, 2010; Pitt, 2008). Information and communication technologies (ICTs) enable enhanced decision making and asset management within an organisation (Campos et al., 2017; Emmanouilidis et al., 2009). However, the pace at which ICT tools and analyses progress has historically outstripped the rate at which decision support tools for infrastructure asset management were updated. There are thus opportunities for infrastructure asset managers to make better use of state-of-the-art tools (e.g. Dorafshan and Maguire, 2018; Vaghefi et al., 2012) that are now cheaper, more easily integrated into other systems and more versatile and configurable than tools that were available several decades ago. Using such technologies to improve and analyse the information contained in asset databases has the potential to enhance decision making, as exemplified by the case of assessing river bank stability in pipe crossings.
Pipelines can be designed to cross rivers beneath a river's bed surface, installed using either trenching or a horizontal directional drill, or above a river's bed surface using a bridge with piers and/or abutments. Bridges may have the sole purpose of supporting a pipeline or may also have other functions, such as supporting roads or railways. River crossings are a particular area of vulnerability in national-scale water infrastructure, energy (oil, gas) and transport networks (ICE, 2009; van Leeuwen and Lamb, 2014) because, compared with buried infrastructure, they are generally exposed and subjected to external factors that speed up their deterioration. Crossings are at risk from both vertical scour and lateral bank erosion (Johnson, 2005; Kim et al., 2013). The latter (Figure 1), particularly for crossing structures that have the sole purpose of supporting pipelines, has been given less attention than the former yet is an important contributor to pipeline crossing damage. For example, we estimate from the Scottish Water (SW) database discussed below that $30 \%$ of pipeline crossings with observed riverbank instability are associated with either leaks or damaged foundations.

Comprehensive manuals for bridge scour assessment are available for the UK (Kirby et al., 2015) and other countries (e.g. Arneson et al., 2012; Coleman and Melville, 2001). These manuals are useful to engineers who design, construct, operate and maintain structures but do not meet the asset management challenges faced by pipeline infrastructure owners because the guidance $(a)$ focuses on transport bridges rather than on above-ground pipe crossings, the latter being more at risk from bank erosion since pipe crossing structures are less likely to have bridge abutments, and $(b)$ is not sufficiently 


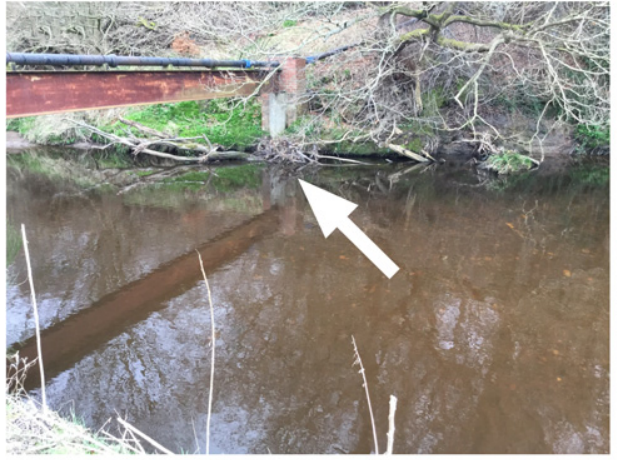

(a)

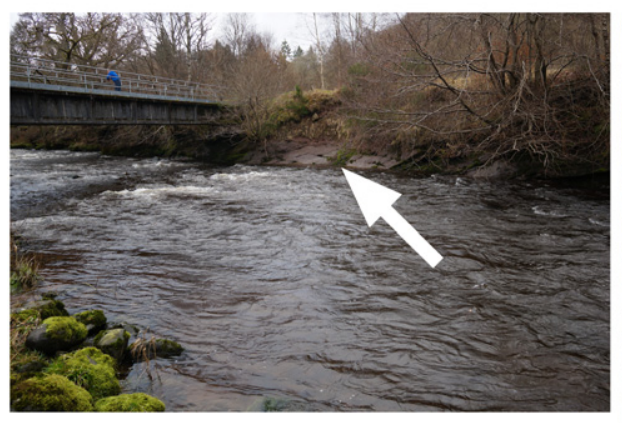

(c)

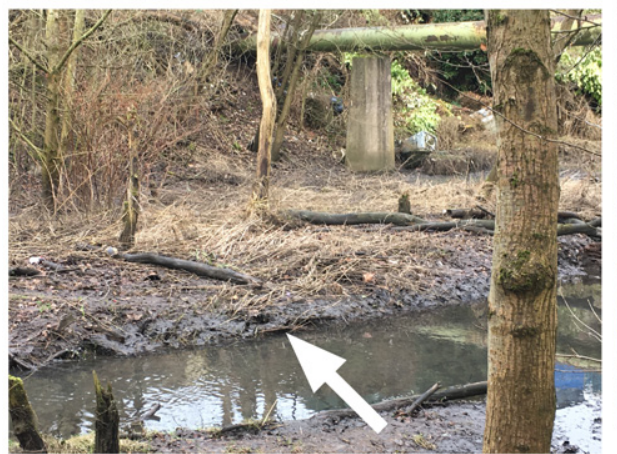

(e)

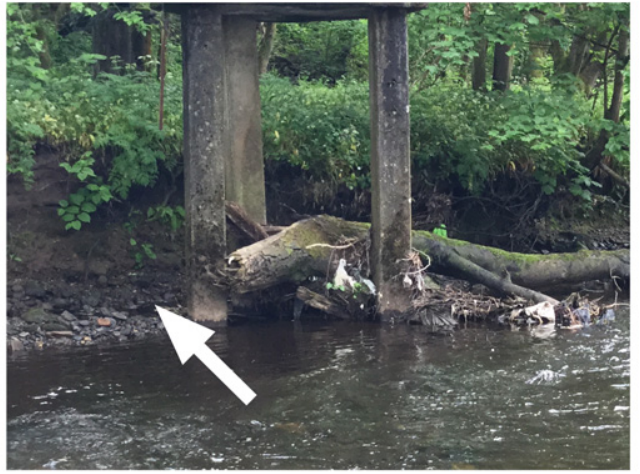

(b)

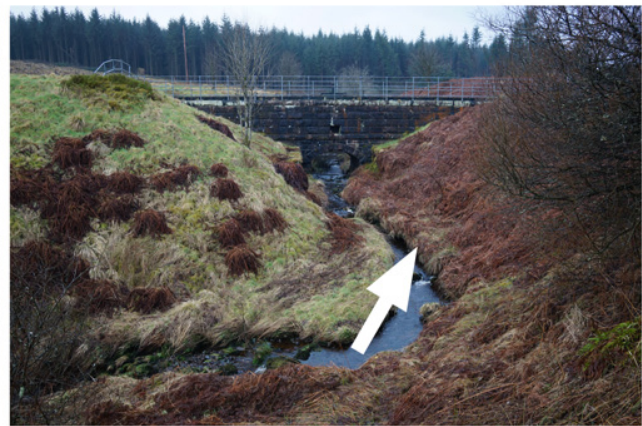

(d)

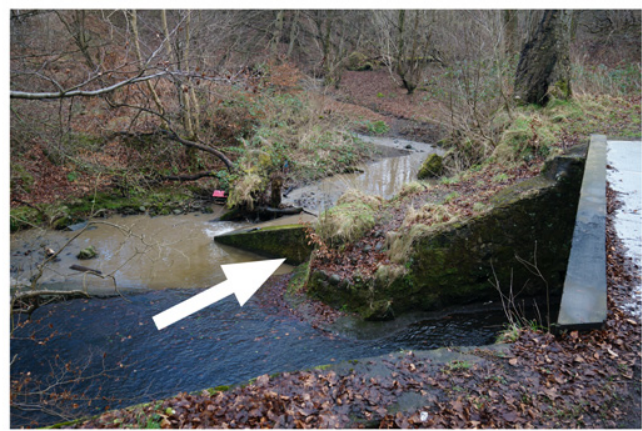

(f)

Figure 1. Example of geomorphological factors affecting bank stability. White arrows point to specific features: (a) bank undercut close to pipe crossing abutment; (b) and (c) bank erosion close to pipe crossing pier and abutment; (d) very steep banks close to crossing;

(e) highly erodible material close to crossing pier; ( $f$ ) undermined bank protection integrated into the crossing abutment construction

comprehensive on how different types of information on river stability can be used to reduce uncertainty when making decisions about what stages of risk assessment to complete. With respect to this latter issue, asset inspections have recently been transformed by the development of bespoke software packages on relatively low-cost mobile computers that have embedded global navigation satellite system technology for positioning using, for example, global positioning system (GPS), Glonass, Galileo and/or BeiDou systems (Xu and Xu, 2016). Such software typically integrates data collection during inspections into geographic information systems (GISs) that include other sets of spatially distributed data such as aerial and satellite imagery, and derived products such as vegetation growth and urban development. Asset management decision making practice has not kept pace with these technological developments in data collection and, for the case of assessing river stability in the vicinity of above-ground pipe crossings, tools are needed to interpret survey data that can be acquired using mobile computers.

A range of geomorphological classification methods have been developed to assess river stability. Examples include the Morph framework (Shuker et al., 2017), the natural channel classification (Beechie and Imaki, 2014), the river styles framework (Brierley and Fryirs, 2013), the fluvial audit method (Sear et al., 2009), and older approaches such as the Rosgen classification system (Rosgen and Silvey, 1996). In addition to bank stability and other geomorphological attributes, many of 
these methods implement a range of ecological and water quality indicators. Data gathering is increasingly complemented by low-cost computational hardware and software such as portable GPS/GIS tools (Connell, 2012). However, to specifically assess bank stability, these techniques require considerable information at the local and catchment scales, as well as input by trained geomorphologists. Ultimately, whichever classification system is used, geomorphic context is critical to separate river reaches based on the capacity of a channel to adjust (Buffington and Montgomery, 2013). The challenge for asset inspection is thus to establish inspection protocols that meet two requirements: $(a)$ to enable rapid collection of data for input into a decision support framework that is informed by contemporary approaches to assess river stability and $(b)$ to be simple and versatile enough to be applied by asset inspectors and managers who do not necessarily have specialist training in river engineering and fluvial geomorphology.

This paper reports on the development of enhancements to SW's field survey protocol and data analysis framework. The impact of these developments is evaluated through a validation exercise using SW's water and wastewater river crossing infrastructure.

\section{Water and wastewater pipeline river crossings in Scotland}

SW provides water and wastewater services to 2.5 million homes and 156000 business properties in Scotland. The drinking water network is $48480 \mathrm{~km}$ long, of which $7000 \mathrm{~km}$ forms the trunk main network. There is an additional $51199 \mathrm{~km}$ of wastewater pipe network (SW, 2018). Across the drinking and wastewater pipe networks there are about 550 and 800 river crossings, respectively (Figure 2). Many of these crossings span rivers of differing size and style, reflecting Scotland's diverse river environments (Perfect et al., 2013) posing a variety of management issues. Known problems include bank erosion, flooding, bridge damage, bed instability, degradation of instream habitat quality and channel confluence alignment (Hoey et al., 1998).

River crossings are vulnerable because they are at risk of failure from high-flow events of varying - and currently unknown magnitudes. This vulnerability was highlighted by bridge failures during floods in northern England and Scotland in

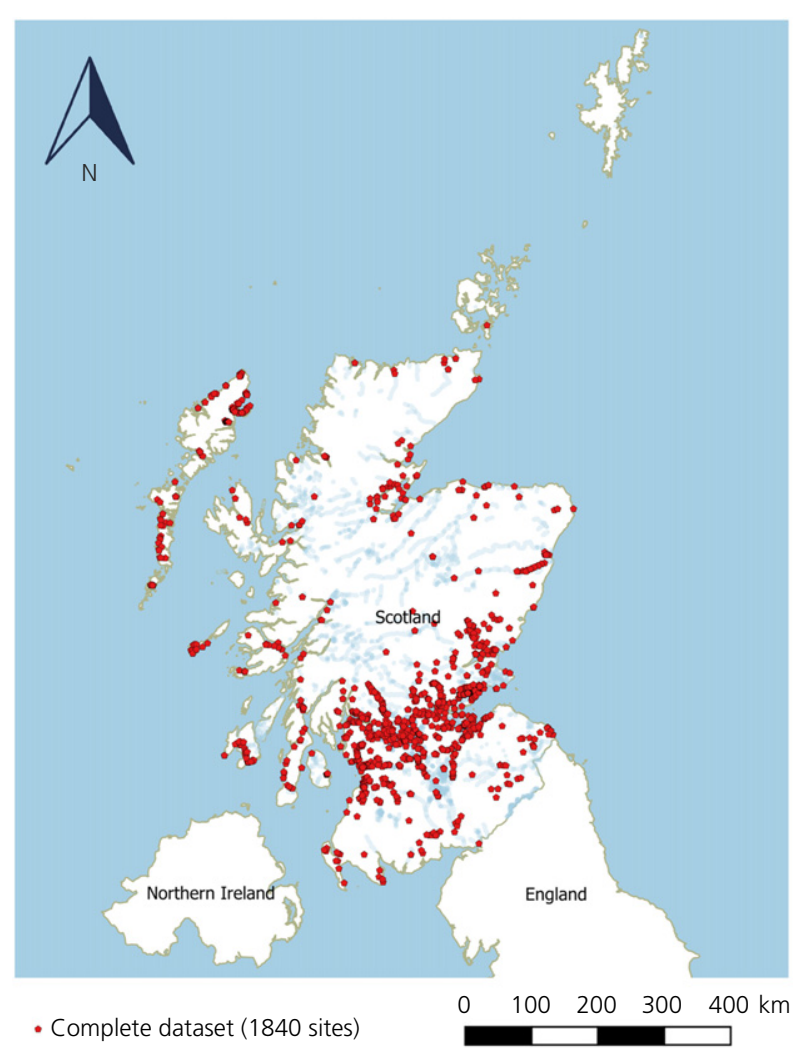

(a)

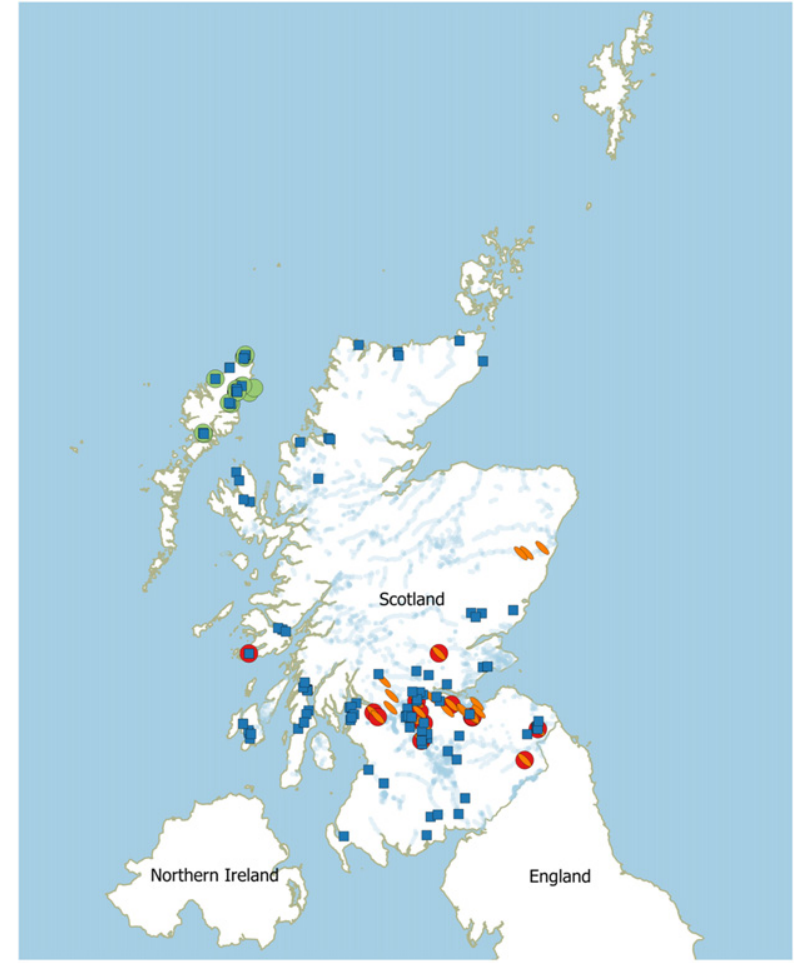

- Phase 1: Preliminary development and assessment Phase 2: User bias

- Phase 3: Consistency of methodology I

- Phase 4: Consistency of methodology II

(b)

Figure 2. Locations of river pipe crossings in Scotland. (a) Distribution of river pipe crossings across the country at time of writing. (b) Pipe crossings used for development and testing of the ERI method described in this paper (listed in Table 2) 
2015/2016 (Barker et al., 2016; Marsh et al., 2016). Data from econometric modelling by SW indicates that the cost of repair and provision of temporary water supplies due to river crossing failure can range from tens of thousands of pounds in simple cases, to tens of millions in the most challenging of examples.

Inspections prior to the current project had identified examples where river instability presented a clear threat to the integrity of a pipe crossing. There were also cases where the effects of river instability were less clear but thought to warrant further assessment. Hence, SW identified the need to develop a decision support framework to

- direct further desk-based assessment of river stability

- identify the need for scour or bank erosion prevention measures

- establish the frequency of repeat asset inspections.

\section{Approaches to bank erosion scoring}

Erosion is the process of sediment removal from a particular location in a landscape. In fluvial environments, eroded sediment is likely to be deposited downstream on a river bar or delta, or deposited overbank on a floodplain. Subsequently, deposited material may be reworked by succeeding cycles of erosion and deposition. The size, geometry and morphology of the river and its banks, properties of the bank material, hydraulics of flow in the channel, river flow hydrology, climatic conditions and vegetation cover are all controlling factors in river bank erosion. However, three major controls have been identified that are independent of the type of river environment: the bank height $(H)$ and its relationship with the average water depth (associated with a critical bank height $H^{\prime}$ ), bank angle (Darby and Thorne, 1996; Osman and Thorne, 1988) and the presence or absence of protective vegetative cover (Micheli and Kirchner, 2002).

A variety of bank erosion scoring indices have been proposed that include the assessment of a number of components (Table 1). The bank erosion susceptibility index (BESI) (Connell, 2012) is an index that requires only four input components and is the only index in Table 1 that has been validated for desk-based assessments using accurately geo-located videos. However, inputs such as bankfull width or root depth can only be extracted from photographs for very specific river environments. The bank erosion hazard index (BEHI) was developed by Rosgen (2001a, 2001b) as part of a wider bank erodibility assessment. BEHI calculations require detailed field measurements and give an in-depth analysis of

Table 1. Summary of the components of a selection of existing erosion indices (based on Connell, 2012)

\begin{tabular}{|c|c|c|c|c|c|c|}
\hline Component & BESI & BEHI & USDoT & EPIN & SEI & BEPI \\
\hline Bank erosion/condition & & & $\checkmark$ & $\checkmark$ & $\checkmark$ & \\
\hline Bank height/bankfull ratio & $\checkmark$ & $\checkmark$ & & & & $\checkmark$ \\
\hline Root depth/bank height ratio & & $\checkmark$ & & & & \\
\hline Bank angle & $\checkmark$ & $\checkmark$ & $\checkmark$ & & $\checkmark$ & $\checkmark$ \\
\hline Vegetation & & $\checkmark$ & $\checkmark$ & $\checkmark$ & $\checkmark$ & $\checkmark$ \\
\hline Surface protection & $\checkmark$ & & & & & \\
\hline Riparian diversity & $\checkmark$ & & & & & \\
\hline Bank material & & & $\checkmark$ & & $\checkmark$ & $\checkmark$ \\
\hline Root density & & $\checkmark$ & & & & $\checkmark$ \\
\hline Velocity & & & $\checkmark$ & $\checkmark$ & $\checkmark$ & \\
\hline Cause of erosion & & & & & $\checkmark$ & \\
\hline Substrate materials & & & $\checkmark$ & $\checkmark$ & & \\
\hline Thalweg location & & & $\checkmark$ & & $\checkmark$ & \\
\hline Degree of incision/constriction & & & $\checkmark$ & & & \\
\hline Deposition & & & $\checkmark$ & & & \\
\hline
\end{tabular}

Table 2. Sequence of testing of the ERI method

\begin{tabular}{|c|c|c|c|c|}
\hline Phase & Purpose & $\begin{array}{l}\text { Number of } \\
\text { sites used }\end{array}$ & Source of information & Test carried out by \\
\hline 1 & $\begin{array}{l}\text { Selection of variables. Determination } \\
\text { of calculation method. Assessment of } \\
\text { whether method correctly identifies sites } \\
\text { particularly susceptible to bank erosion }\end{array}$ & 13 & $\begin{array}{l}\text { Assets selected from online asset } \\
\text { database that SW considered } \\
\text { to be particularly susceptible } \\
\text { to bank erosion }\end{array}$ & UoG (1 geomorphologist) \\
\hline 2 & User bias & 31 & Online asset database & $\begin{array}{l}\text { UoG ( } 1 \text { geomorphologist) and SW } \\
\text { (3 assessors) }\end{array}$ \\
\hline 3 & Consistency of methodology I & 23 & $\begin{array}{l}\text { Online asset database for all sites in } \\
\text { Outer Hebrides; field inspection }\end{array}$ & $\begin{array}{l}\text { UoG (field-based geomorphologist) } \\
\text { and SW (database) }\end{array}$ \\
\hline 4 & Consistency of methodology II & 118 & $\begin{array}{l}\text { Random selection from online } \\
\text { asset database }\end{array}$ & $\begin{array}{l}\text { UoG (1 geomorphologist) and SW } \\
\text { (1 assessor) }\end{array}$ \\
\hline
\end{tabular}


bank stability. This index is extensively used in academia and industry, despite criticism of the broader Rosgen approach to natural channel design (e.g. Simon et al., 2007). BEHI and BESI (WDNR, 2010a, 2010b) differ only on the type of required inputs and they follow almost identical reasoning and methodology. The US Department of Transportation index (USDoT) (Johnson, 2006) requires 13 independent inputs, all of which need to be measured in the field. This index results in a detailed estimation for bank stability and is often the starting point for compatible river habitat assessments. The erosion potential index number (EPIN) (G/FLRPC, 1998) is calculated from the sum of scores for bed material, slope condition value, vegetation and averaged hydraulics. The EPIN requires information that cannot be extracted from photographs. However, it was historically the first erosion index that accounted for surveying efficiency (less inputs for more coverage; 221 successful assessments in less than a year). The streambank erosion inventory (SEI) (MDEQ, 2001) includes field-based bank erosion measurements but was mainly used as a river management inventory recording (e.g. river accessibility, condition, vegetative cover and apparent cause of erosion) (Seelbach, 1997).

To summarise, Table 1 shows that a number of semi-empirical indices have been developed that use different types of qualitative and quantitative data and have gone through different degrees of validation. The extensive review of existing riverbank erosion indices by Connell (2012) showed that three of the methods have a clear focus on assessing bank erosion, in contrast to the majority of methods that have bank erosion as an input concentrate on habitat or water quality assessments. These methods are the BESI, BEHI and bank erosion potential index (BEPI) (WDNR, 2010a, 2010b). Table 1 provides an overview of the input variables used in each method. The three methods are similar in scope and development and all three include the bank height/bankfull depth ratio and bank angle as inputs. The main difference between the methods is that both the BEHI and BEPI require an estimate of root density for calculating an erosion index score, but the BESI method does not. Although the inclusion of vegetation is similar for the three methods, the BESI method requires only a reference for any existing surface protection and an estimate of riparian diversity. Finally, the BESI is the only method that has been applied using state-of-the-art data acquisition techniques (detailed topographical surveys, digital terrain model analysis and geo-located video inputs); all the other methods require field measurements that are typically beyond the scope of asset management inspections).

\section{Methodology}

In early 2016, SW began a programme of planned inspections of all pipe crossings as part of its developing water and wastewater infrastructure strategies. A customised app, for a ruggedised tablet computer, was used as a low-cost device to acquire baseline data on each of the crossings. The data captured varies, as appropriate, from simple yes/no responses, through multiple choice answers, to free text. The app also includes a form to acquire geo-referenced images. A protocol for data acquisition to assess bank erosion was implemented in surveys performed after October 2017 (Figure 3). The collected data, photographs and notes are stored in an online database for

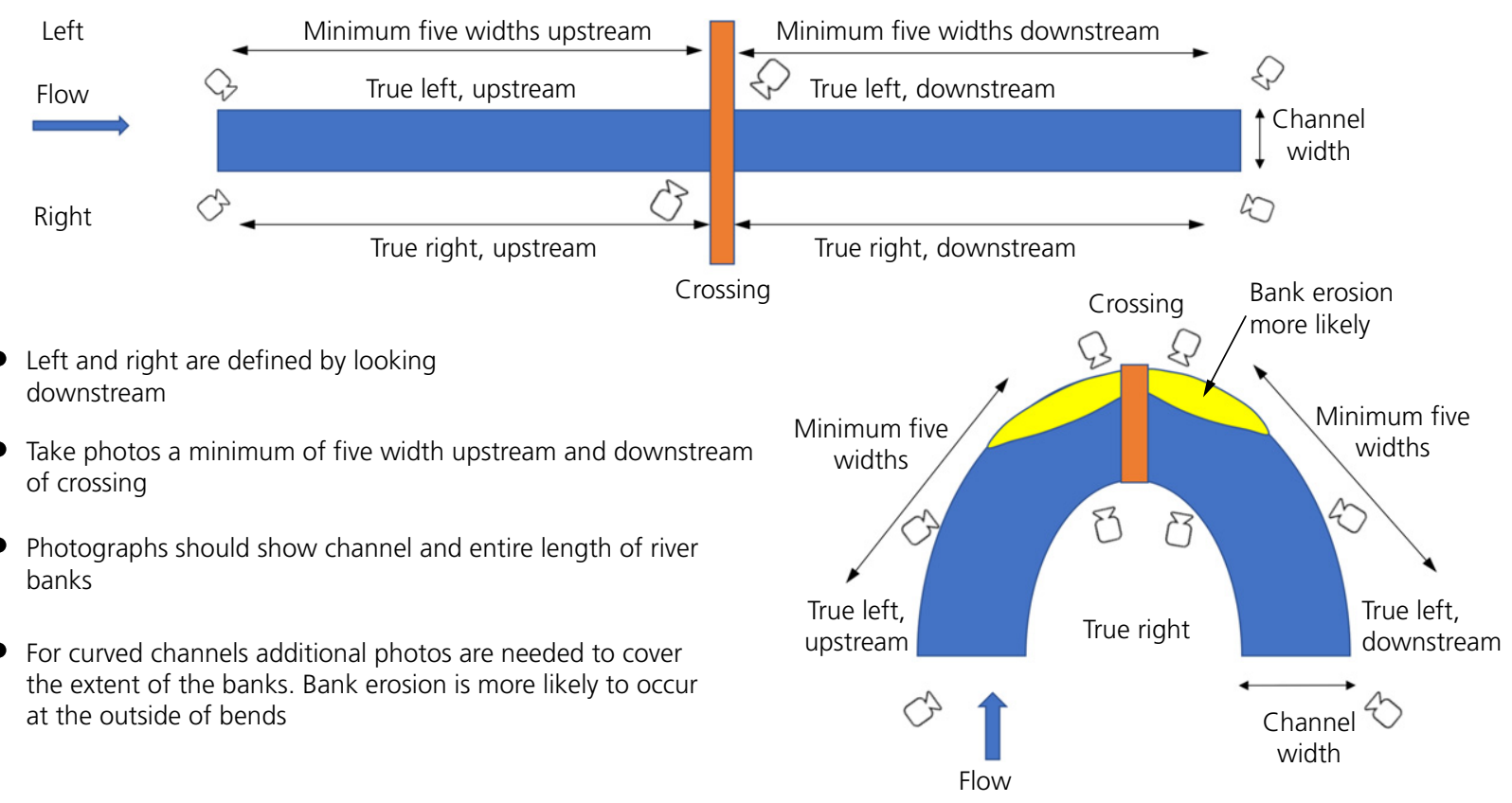

Figure 3. Suggested protocol for collection of photographs during surveying. Simple rules are suggested to ensure that the photographs can be used for a first-order geomorphological assessment 
each one of the surveyed assets. All the desk-based assessments presented in this paper were performed using information and photographs stored in this database.

This paper reports on a simplified and purpose-specific bank stability assessment that was developed using the frameworks described in Section 3. Individually, none of the bank erosion scoring methods presented in Section 3 were suitable for the determination of erosion risk since they all require detailed geomorphological assessment for each site or high-resolution digital terrain models that do not yet exist for all crossings in Scotland. However, these scoring methods provided a framework for the development of a new empirical scoring system, called the erosion risk index (ERI). The score that is calculated for a particular asset and incorporates an assessment of data quality (DQ) is termed the ERI*. The main challenge was to replace quantitative geomorphological inputs (such as bank height and bankfull depth) with qualitative evidence for erosion risk that can be determined directly from site photographs. In parallel, it was necessary to consider the quality of the data, the ease of application and the compatibility of this system with the existing risk scoring classes used by SW.

The ERI method was developed and tested in four phases (Table 2). The first phase focused on identifying the input variables and scoring method for the ERI. The second phase investigated user bias, and the third and fourth phases investigated the consistency of the methodology. For phase 1, the selection of sites was random. For phases 2 to 4 , the sites were selected in a manner that allowed for the progressive increase of the variability of geomorphological settings - phase 2 used sites in the Outer Hebrides, phase 3 primarily used sites from the central belt of Scotland with the addition of five sites of similar morphology from other areas and phase 4 used a diverse sample from across Scotland (Figure 2). All four phases used data from SW's asset inspection online database. The assessments undertaken during phases 2 and 4 were supplemented by data from field visits to 23 assets in the Outer Hebrides.

\section{Results}

\subsection{Phase 1 - selection of variables, determination of calculation method and assessment of ability to identify sites susceptible to erosion}

The main purpose of the methodology was to assess the risk of bank erosion based on photographs taken by surveying personnel who may not be professional geomorphologists. This led to the exclusion of morphological indicators that are difficult to determine directly from photographs such as the height of the bank. However, qualitative geomorphological indicators such as bank angle and the presence of vegetation were included and characterised using interval measurement scales. In addition, bank protection was characterised by its type and also in terms of its condition, reflecting the degree of protection offered. Table 3 shows the input variables that were identified to form this new ERI. Each variable was scored on a scale of $0-5$. The number of graduations in this scale match those used by SW for other components of their asset risk management framework. Where it was not feasible to score a variable using all points in the scale, the number of points was reduced by removing the intermediate values 2 and 4 .

Using the input variables defined in Table 3, the next steps were to develop an index to use for classification and to ensure this index was capable of correctly identifying sites susceptible to erosion. The formulation of such an index can be carried out in many ways, with weightings designed to reflect local conditions. Four formulae were examined -a probabilistic weighted index, a weighted addition, simple multiplication and a weighted scaled mean. Scaling of the index was necessary to secure compatibility with SW's existing asset risk assessments that consider the structural condition and safety of pipes and associated infrastructure. After scaling, the total score was rounded up to an integer value from 1 to 5 . This rounding is common practice in classification for engineering applications as it is preferable for an asset to be classified as more susceptible when the arithmetic index falls between two classes. After rounding, the only formula that provided sufficient separation between the different sites was the weighted scaled mean (WSM) given by Equation 1 (with the terms defined in Table 3).

$$
\mathrm{ERI}=\text { Mean }
$$

1. $\left[\mathrm{AE}_{5 \mathrm{w}}, V, \beta,\left\{0 \cdot 16 \times\left(\mathrm{BP}_{\mathrm{u}} \times\right.\right.\right.$ Condition $\left.\left._{\mathrm{BPu}}-1\right)+1\right\}$,

$$
\left.\left\{0 \cdot 16 \times\left(\mathrm{BP}_{5 \mathrm{w}} \times \text { Condition }_{\mathrm{BP} 5 \mathrm{w}}-1\right)+1\right\}\right]
$$

The ERI values obtained from Equation 1 were then adjusted using a DQ score to reflect the quality of photographic evidence in the database (Equation 2). The ERI was multiplied by five as there are five independent terms in Equation 1.

$$
\text { 2. } \mathrm{ERI}^{*}=(5 \times \mathrm{ERI}+\mathrm{DQ}) / 6
$$

The DQ score for a site uses the number of zeros for the input variables defined in Table 3 that represent the absence of photographic evidence of sufficient quality within the asset database. The DQ values are defined in Table 4. Calculation of ERI* using Equation 2 is not performed if the DQ is low.

The calculations from Equations 1 and 2 are useful only if they correctly identify sites susceptible to erosion. The sensitivity and appropriateness of ERI* were tested using 13 sites that SW considered to be particularly susceptible to bank erosion. These 13 sites were identified based on keyword searching in the asset management database prior to implementation of the outcomes from the present project. All of the 13 sites had ERI* scores $\geq 3$ (Figure 4), defined as medium-risk sites, 
Table 3. Input variables for the ERI

\begin{tabular}{|c|c|c|c|c|c|c|}
\hline Variable & Description & Scale & Description & Application & Description & Calculation \\
\hline \multirow[t]{4}{*}{$A E_{u}$} & \multirow[t]{4}{*}{$\begin{array}{l}\text { A. Active bank erosion } \\
\text { beneath the crossing }\end{array}$} & 0 & $\begin{array}{l}\text { No or unsatisfactory } \\
\text { photographic evidence }\end{array}$ & $\mathrm{AEL}_{\mathrm{u}}$ & $\begin{array}{l}\text { A1. Erosion beneath } \\
\text { the crossing, left } \\
\text { bank }\end{array}$ & $A E_{u}=\max \left(A E L_{u}, A E R_{u}\right)$ \\
\hline & & 1 & $\begin{array}{l}\text { Absence of evidence of } \\
\text { bank erosion }\end{array}$ & $A E R_{u}$ & $\begin{array}{l}\text { A2. Erosion beneath } \\
\text { the crossing, right } \\
\text { bank }\end{array}$ & \\
\hline & & 3 & Evidence of bank erosion & & & \\
\hline & & 5 & $\begin{array}{l}\text { Evidence of severe bank } \\
\text { erosion }\end{array}$ & & & \\
\hline \multirow[t]{4}{*}{$A E_{5 w}$} & \multirow[t]{4}{*}{$\begin{array}{l}\text { B. Active bank erosion five } \\
\text { channel widths ( } 5 \mathrm{w}) \\
\text { upstream or downstream } \\
\text { of the crossing }\end{array}$} & 0 & $\begin{array}{l}\text { No or unsatisfactory } \\
\text { photographic evidence }\end{array}$ & $\mathrm{AEUL}_{5 \mathrm{w}}$ & $\begin{array}{l}\text { B1. Erosion upstream } \\
\text { of the crossing, left } \\
\text { bank }\end{array}$ & $\begin{array}{l}A E_{5 w}=\max \left(A E U L_{5 w}\right. \\
A E U R_{5 w}, A E D L_{5 w} \\
\left.A E D R_{5 w}\right)\end{array}$ \\
\hline & & 1 & $\begin{array}{l}\text { Absence of evidence of } \\
\text { bank erosion }\end{array}$ & $\mathrm{AEUR}_{5 \mathrm{w}}$ & $\begin{array}{l}\text { B2. Erosion upstream } \\
\text { of the crossing, right } \\
\text { bank }\end{array}$ & \\
\hline & & 3 & Evidence of bank erosion & $A E D L_{5 w}$ & $\begin{array}{l}\text { B3. Erosion } \\
\text { downstream of the } \\
\text { crossing, left bank }\end{array}$ & \\
\hline & & 5 & $\begin{array}{l}\text { Evidence of severe } \\
\text { bank erosion }\end{array}$ & $\mathrm{AEDR}_{5 \mathrm{w}}$ & $\begin{array}{l}\text { B4. Erosion } \\
\text { downstream of the } \\
\text { crossing, right bank }\end{array}$ & \\
\hline \multirow[t]{4}{*}{$\mathrm{BP}_{\mathrm{u}}$} & \multirow[t]{4}{*}{$\begin{array}{l}\text { C1. Bank protection } \\
\text { beneath } \\
\text { the crossing }\end{array}$} & 0 & $\begin{array}{l}\text { No or unsatisfactory } \\
\text { photographic evidence }\end{array}$ & $\mathrm{BPL}_{\mathrm{u}}$ & $\begin{array}{l}\text { C1a. Bank protection } \\
\text { beneath the crossing, } \\
\text { left bank }\end{array}$ & $\mathrm{BP}_{\mathrm{u}}=\max \left(\mathrm{BPL}_{\mathrm{u}}, \mathrm{BPR}_{\mathrm{u}}\right)$ \\
\hline & & 1 & $\begin{array}{l}\text { Hard structure (concrete/ } \\
\text { masonry/steel piles) }\end{array}$ & $\mathrm{BPR}_{\mathrm{u}}$ & $\begin{array}{l}\text { C1b. Bank protection } \\
\text { beneath the crossing, } \\
\text { right bank }\end{array}$ & \\
\hline & & 3 & $\begin{array}{l}\text { Soft structure (rip-rap, } \\
\text { gabion basket, other) }\end{array}$ & & & \\
\hline & & 5 & No protection & & & \\
\hline \multirow[t]{4}{*}{$\mathrm{BP}_{5 \mathrm{w}}$} & \multirow[t]{4}{*}{$\begin{array}{l}\text { C2. Bank protection five } \\
\text { channel widths upstream } \\
\text { or downstream }\end{array}$} & 0 & $\begin{array}{l}\text { No or unsatisfactory } \\
\text { photographic evidence }\end{array}$ & $\mathrm{BPUL}_{5 \mathrm{w}}$ & $\begin{array}{l}\text { C2a. Bank protection } \\
\text { upstream of the } \\
\text { crossing, left bank }\end{array}$ & $\begin{array}{l}\mathrm{BP}_{5 \mathrm{w}}=\max \left(\mathrm{BPUL}_{5 \mathrm{w}}\right. \\
\mathrm{BPUR}_{5 \mathrm{w}}, \mathrm{BPDL}_{5 \mathrm{w}} \\
\left.\mathrm{BPDR}_{5 \mathrm{w}}\right)\end{array}$ \\
\hline & & 1 & $\begin{array}{l}\text { Hard structure (concrete/ } \\
\text { masonry/steel piles) }\end{array}$ & $\mathrm{BPUR}_{5 w}$ & $\begin{array}{l}\text { C2b. Bank protection } \\
\text { upstream of the } \\
\text { crossing, right bank }\end{array}$ & \\
\hline & & 3 & $\begin{array}{l}\text { Soft structure (rip-rap, } \\
\text { gabion basket, other) }\end{array}$ & $B P D L_{5 w}$ & $\begin{array}{l}\text { C2c. Bank protection } \\
\text { downstream of the } \\
\text { crossing, left bank }\end{array}$ & \\
\hline & & 5 & No protection & $\mathrm{BPDR}_{5 w}$ & $\begin{array}{l}\text { C2d. Bank protection } \\
\text { downstream of the } \\
\text { crossing, right bank }\end{array}$ & \\
\hline \multirow[t]{5}{*}{ Condition } & \multirow[t]{5}{*}{$\begin{array}{l}\text { Condition of bank } \\
\text { protection }\end{array}$} & 1 & $\begin{array}{l}\text { Undamaged - intact } \\
\text { as-new condition }\end{array}$ & & & \\
\hline & & 2 & $\begin{array}{l}\text { Minor damage - intact but } \\
\text { with some isolated damage }\end{array}$ & & & \\
\hline & & 3 & $\begin{array}{l}\text { Moderate - intact but with } \\
\text { widespread damage }\end{array}$ & & & \\
\hline & & 4 & $\begin{array}{l}\text { Severe damage - intact but } \\
\text { likely to fail and remedial } \\
\text { work required to stabilise } \\
\text { bank }\end{array}$ & & & \\
\hline & & 5 & $\begin{array}{l}\text { Failed - in pieces, offers no } \\
\text { protection }\end{array}$ & & & \\
\hline \multirow[t]{3}{*}{$\beta$} & \multirow[t]{3}{*}{ D. Bank angle } & 1 & $<30^{\circ}$ & & & \\
\hline & & 3 & $30-80^{\circ}$ & & & \\
\hline & & 5 & $>80 \%$ undercut & & & \\
\hline \multirow[t]{3}{*}{ V } & \multirow[t]{3}{*}{ E. Vegetation } & 1 & Both high and low vegetation & & & \\
\hline & & 3 & Either low or high vegetation & & & \\
\hline & & 5 & $\begin{array}{l}\text { No vegetation or very } \\
\text { sparse cover }\end{array}$ & & & \\
\hline
\end{tabular}


Table 4. Attribution of DQ scores according to the presence and quality of photographic evidence for the input variables defined in Table 2

\begin{tabular}{|lc} 
DQ score & $\begin{array}{c}\text { Number of input variables with no or } \\
\text { unsatisfactory photographic evidence }\end{array}$ \\
\hline 0 & 0 \\
5 & $1-3$ \\
Low data quality & $4-5$ \\
\hline
\end{tabular}

Calculation of ERI* using Equation 2 is not performed if the DQ is low

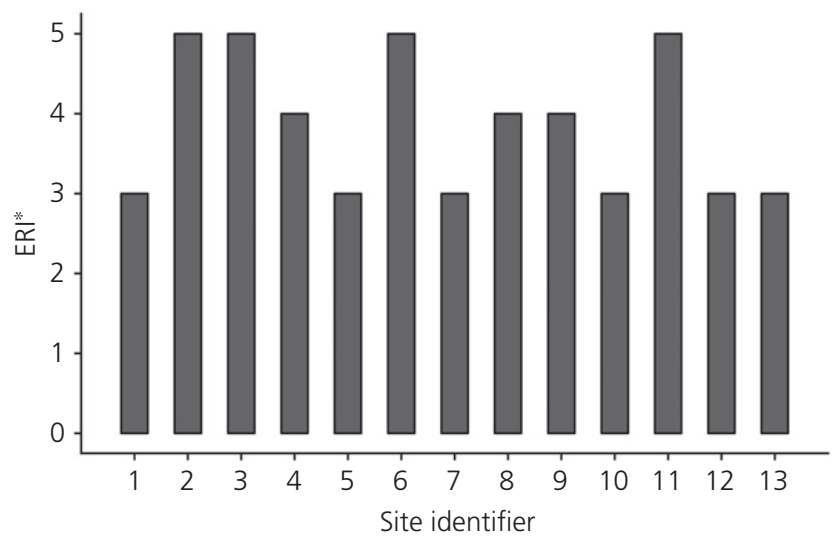

Figure 4. Initial testing of $\mathrm{ERI}$ * for 13 sites (phase 1; Table 2) that were identified to be particularly susceptible to bank erosion from keyword searches of the asset management database prior to the current project

susceptible to erosion due to particular geomorphological characteristics. Thus, all sites' ERI* values were consistent with SW's prior independent assessments of erosion risk, thus demonstrating the capability of the ERI to identify sites that are particularly susceptible to bank erosion.

\subsection{Phase 2 - user bias}

To assess the effect of user bias on the ERI (phase 2; Table 3), 31 further sites were evaluated using the scoring method outlined above by an expert geomorphologist (using both the online database and site visits) and three SW employees (using the online database only). Figure 5 compares the scores obtained by these different operators and suggests convergence of the results, implying the limited sensitivity of the method to user bias. The sites scored with the DQ identifier were highlighted as having poor DQ in the online database as photographs either did not clearly show the banks close to the crossing or were taken when dense summer vegetation obscured the banks.

\subsection{Phases 3 and 4 - consistency of methodology}

Testing of the consistency of the methodology was separated into two phases (Table 2). In phase 3, 23 sites from the Outer Hebrides were assessed by SW using the online database. Field data for these same sites were then collected by University of
Glasgow (UoG) using the ERI categories (Figure 6). In phase 4 , a randomly selected set of 118 sites was scored by a UoG geomorphologist and a SW assessor, both using the online database (Figure 6).

For phase 3, Figure 6 suggests that the desk-based assessment overestimated the ERI score from direct field observations for 14 out of 23 sites, four sites gave the same score and one site was scored with a higher ERI (4) from field assessment than from the desk-based scoring. Four sites in the online database were identified by the SW assessor as inadequate for performing a desk-based calculation of the ERI.

For phase 4, comparison of desk-based calculations of the ERI by SW and UoG assessors (Figure 7) demonstrated agreement for 69 of the 118 sites $(58 \%)$. A total of 25 sites were identified as having low photographic quality and ERI* $=0$ (nine sites by SW and 16 sites by the UoG geomorphologist). For the remaining 24 cases showing disagreement, the differences were all either +1 (SW scores the ERI higher than the $\mathrm{UoG}$ geomorphologist) or -1 ( $\mathrm{SW}$ score is lower).

For the 118 surveys used in phase 4, the differences in scores were analysed (Figure 8). The discrete nature of the data prohibits the application of traditional regression techniques, so Figure 8 is a graphical representation of the differences in ERI* scores plotted against the calculated scores. The differences follow very similar patterns, suggesting that the differences in scores were not systematically biased by the severity of bank erosion risk.

\section{Discussion}

\subsection{Evaluation of the ERI}

The results from testing the ERI and scoring using the ERI* formula, which takes into account photographic DQ, suggest that the approach is suitable for a first-order classification of assets in relation to their exposure to river bank erosion, using photographic evidence stored in SW's database. The index produces classification of pipeline crossings in a way that is compatible with SW's asset risk assessment scale (1 to 5 from low to high risk; Equation 1) and produces a reliable identification of high-risk sites (Figure 4).

Comparisons between the scores generated by SW's assessors and UoG geomorphologists showed no systematic or structured bias (Figure 5) and a significant proportion of the differences involved the evaluation of the photographic evidence held in the online database (Figures 5 and 7). Furthermore, absolute differences between different ERI* scorings from desk-based assessments very rarely exceeded 1, again indicating the low sensitivity of the ERI to user bias. One area where user interpretations did differ significantly was in the assessment of photographs as unsatisfactory for the required purpose. Training of database users and the provision of examples of 


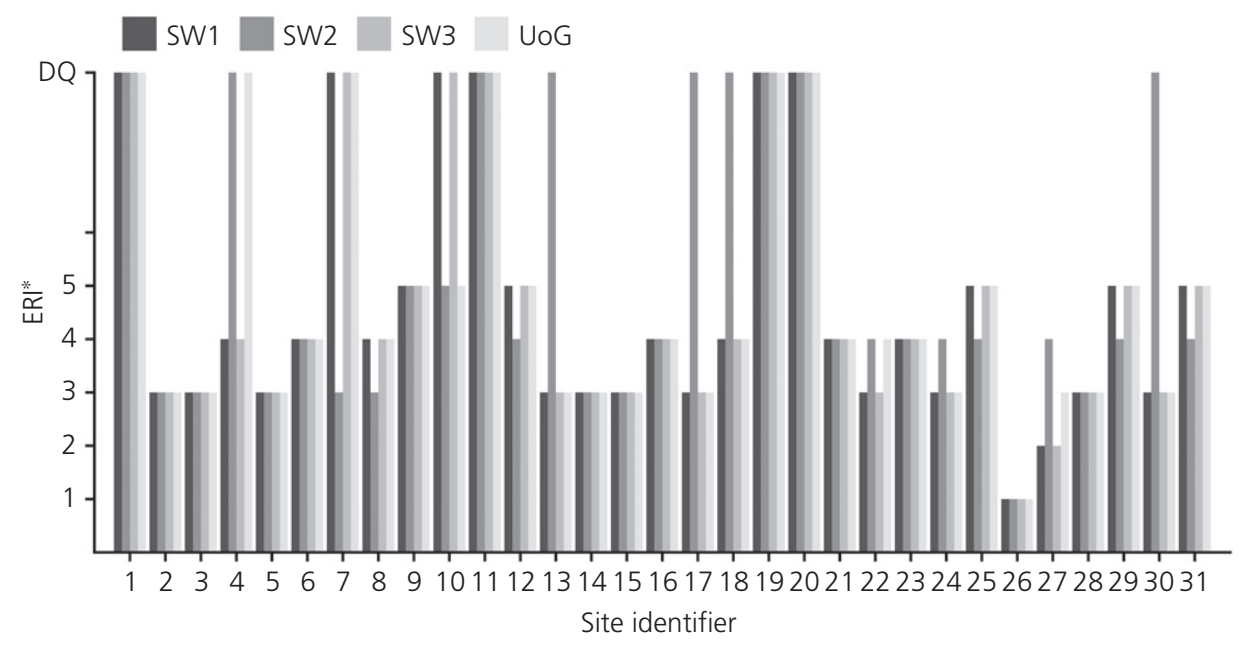

Figure 5. Testing for user bias at 31 crossings (phase 2; Table 2). The comparison is between three assessors from SW (SW1 to SW3) and one UoG geomorphologist. DQ indicates sites that could not be scored using the ERI because of inadequate photographic evidence in the online database

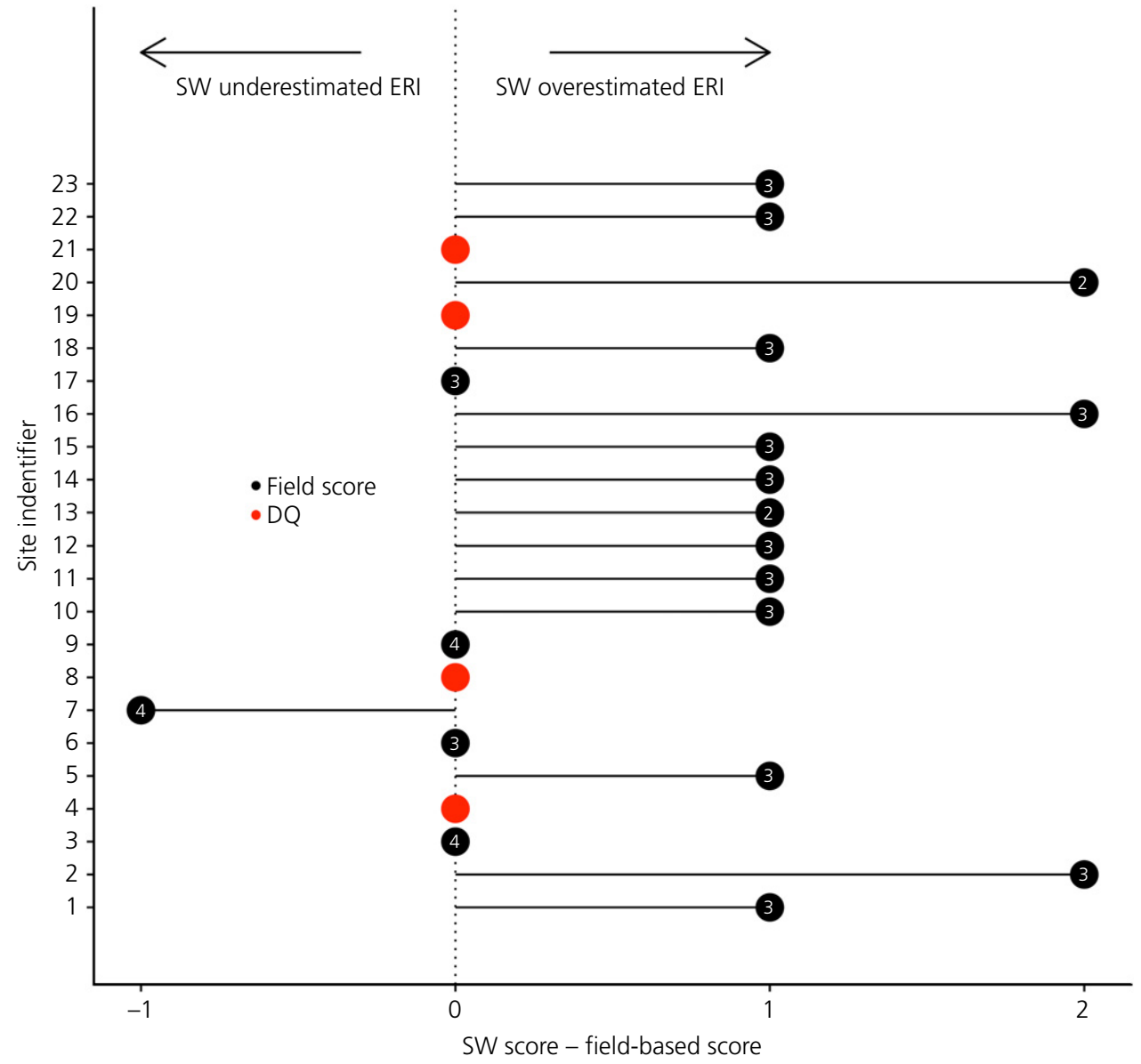

Figure 6. Differences between field measurements from UoG geomorphologists and desk-based ERI assessment from SW assessors, used to assess consistency of the methodology (phase 3; Table 2). Numbers in circles are field ERI scores. The circles without numbers indicate sites for which the database included insufficient photographical evidence to calculate the ERI score 

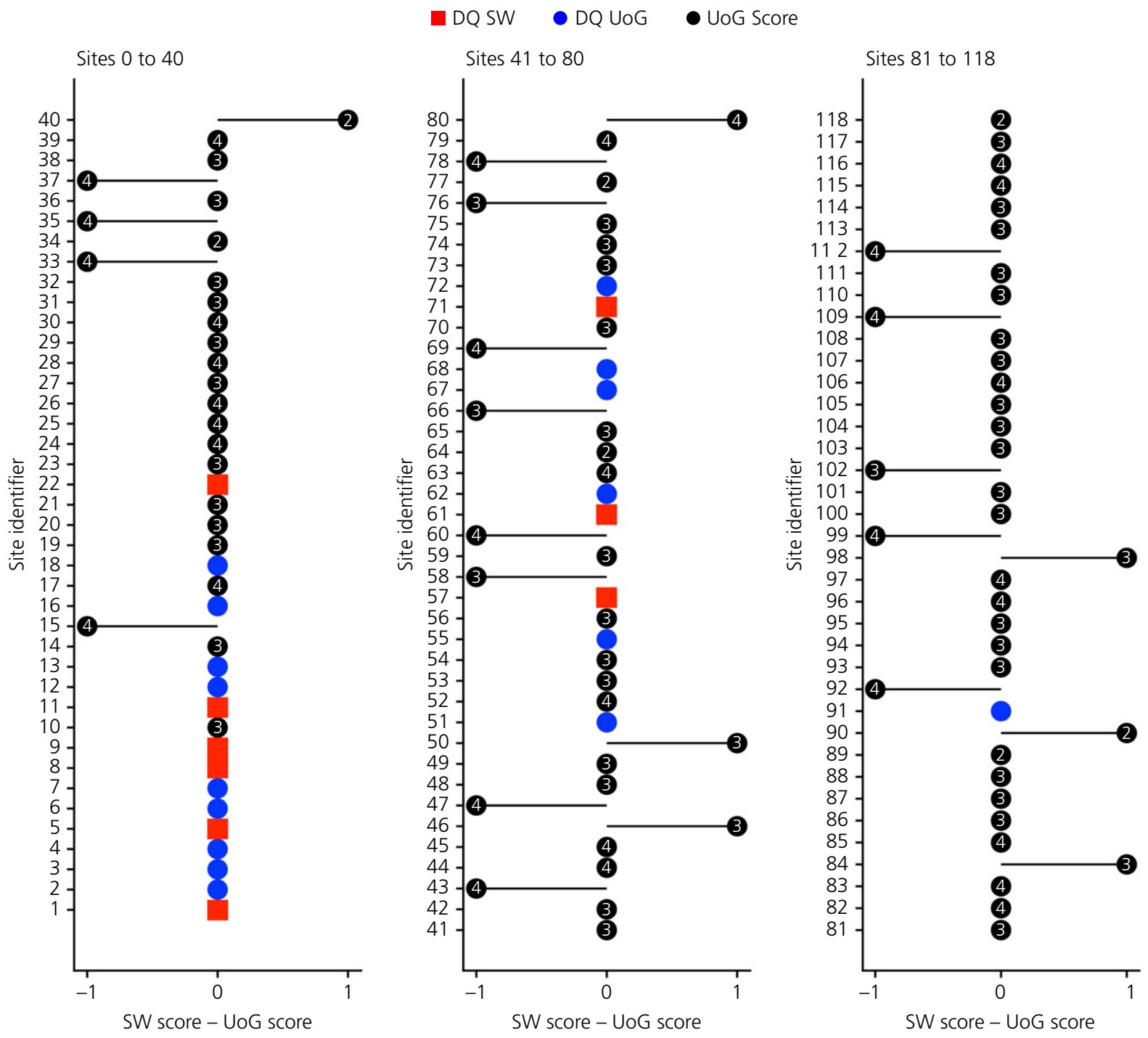

Figure 7. Comparison of desk-based ERI scoring by SW and a UoG used to assess the consistency of the methodology (phase 4; Table 2). Numbers in circles are the ERI scores derived by the UoG geomorphologist. The symbols without numbers (squares (identified by SW) and circles (identified by UoG)) represent sites for which the database included insufficient photographical evidence to calculate an ERI score

unsuitable images that lack the required visual information is recommended to reduce this problem.

A characteristic of desk-based ERI calculations is the tendency to overestimate the risk of bank erosion compared with fieldbased assessments using the same classification. The ERI is based on a simplified classification that can be applied to photographs and so cannot match the experience of a trained geomorphologist in the field. However, the desk-based ERI scores systematically overestimate bank erosion risk so that critical high-risk cases are very likely to be identified as requiring further assessment. Since the ERI aims to produce an initial classification to inform decision making, this tendency for overestimation is a positive characteristic of the method.
A comparison between ERI and other first-order morphological assessments cannot be direct as all the existing approaches (Table 1) rely heavily on targeted field measurements. A good example here is the USDoT index (Johnson, 2005, 2006), which is focused on assessing the stability of bridges using a set of inputs that can be rapidly assessed in the field. However, this assessment requires experience in geomorphological surveying. Components such as channel confinement, floodplain activity or emerging flow patterns cannot be assessed by nonspecialist personnel. In addition, the classification of simpler components, such as bank slope, relies on the selection of class ranges that cannot be determined from photographic input. Specifically, bank slope for the USDoT method includes an additional assessment of the composition of the bank 

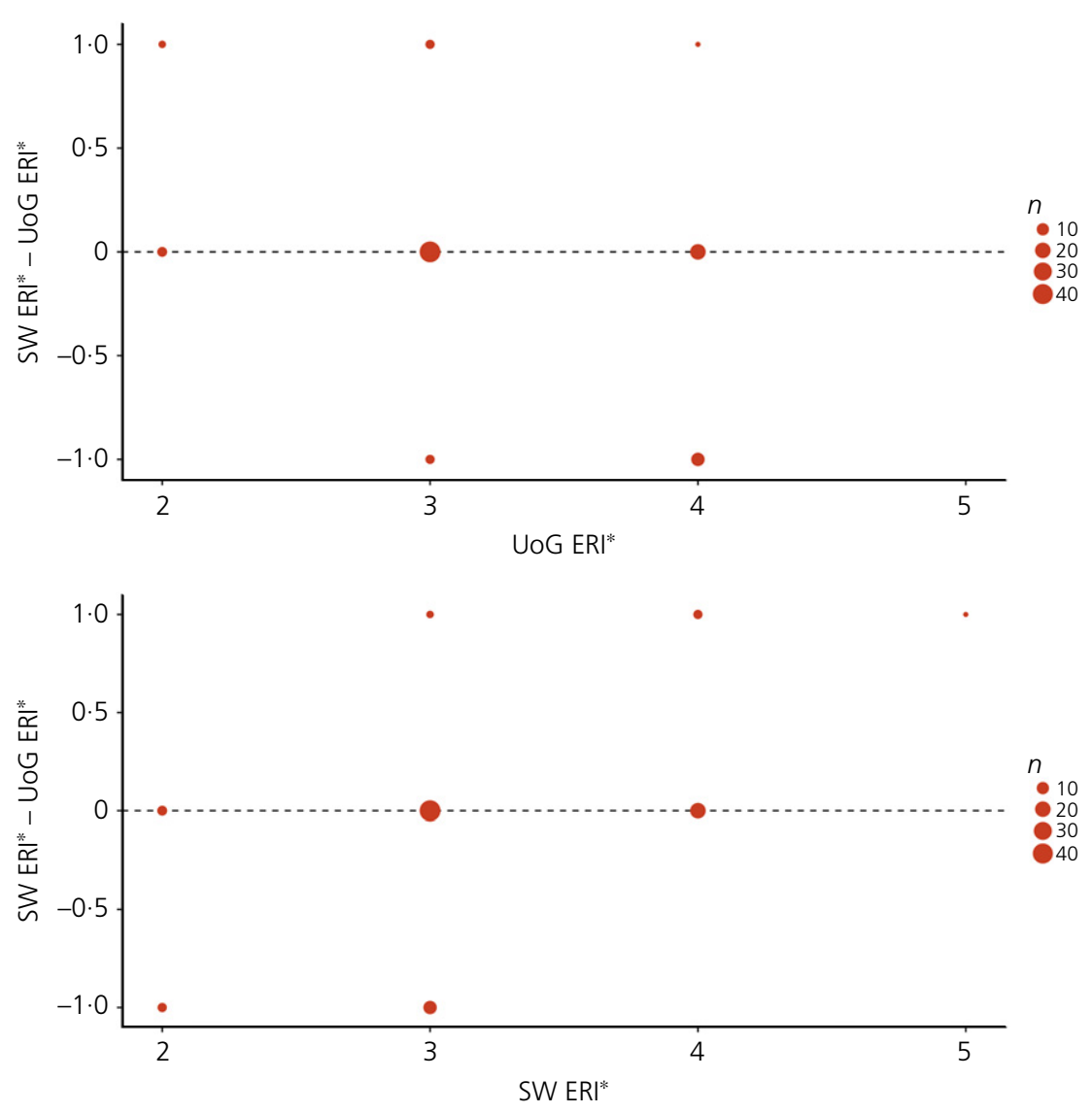

Figure 8. Counts plot of differences in ERI* scores between SW assessors and UoG geomorphologist for 118 sites, used to assess the consistency of the methodology (phase 4; Table 2)

material (Johnson, 2005), which can only be reliably determined from physical sampling. Overall, existing methods such as the USDoT index do not correspond to the type of first-order analysis presented in this paper. The unique characteristic of the ERI is its ability to filter and classify assets from large photographic databases that have been acquired by inspectors without formal geomorphological training, making it versatile for the national-scale assessment of spatially distributed infrastructure assets.

\subsection{Using the ERI in a multi-factor risk assessment system}

The overall aim of SW's risk assessment system for pipeline crossings is to identify where a change in the infrastructure's environment causes a change in risk. The system thus includes components for health and safety, and structural integrity, in addition to erosion risk. Since the inspection of pipeline crossings involves high access costs because the assets are spatially distributed (Figure 2), there is a need for each component of the risk assessment system to identify specific actions that need be taken in response to the resulting classification, including the frequency of subsequent asset inspections. For recommendations to be effective, both the specific site characteristics indicated by each class and the capacity of the organisation to undertake repeated asset inspections need to be considered. For the erosion risk component, the interpretation of each ERI* class to aid in follow-up decision making is as follows.

- $\mathrm{ERI}^{*}=5$, immediate risk. Sites with severe ongoing bank erosion. Sites in this category require immediate further inspection and geomorphological assessment to assess the risk of bank failure and damage to the pipeline crossing.

- ERI* $=4$, high risk. Sites with ongoing erosional processes. Many of these sites have ongoing bank erosion upstream and/or downstream of the crossings. Their geomorphological characteristics, such as low bank angles, are not expected to lead to rapid bank failure during normal high-flow conditions. These sites require immediate further inspection and geomorphological assessment.

- ERI* $^{*}=3$, medium risk. Sites where erosion is not occurring at present, but have geomorphological characteristics that suggest that erosion and potential bank failure may occur during high flows. Many of these sites have existing bank protection that reduces the risk of erosion. As a result, these sites should be considered for 
routine re-survey every few years and should always be re-surveyed after major flood events to ensure that the protection is in good condition.

- $\mathrm{ERI}^{*}=2$, low risk. Sites where visible erosion is absent and their geomorphological characteristics do not enhance erosional processes. There are mainly small rivers with low bed slope and low bank angle that are not likely to be a significant threat to pipe crossing structures. Re-survey can be infrequent, except when other interventions such as construction or removal of a structure or upstream river restoration are likely to change the characteristics of the local environment.

- ERI* $^{*}=1$, minimal risk. Sites where river stability does not impact the pipe crossing structure. These mainly comprise large bridges that accommodate part of the pipe network or crossings that are high above the river, as found in river gorges. The pipe crossing structures are unlikely to be eroded or damaged by river bank erosion.

The ERI* is only calculated when there is sufficient photographic evidence for scoring (Table 4). Thus, if there are missing or poor-quality images, the ERI* can only be calculated after a further asset inspection to acquire appropriate imagery. The scoring system can be directly applied or adapted for use by infrastructure owners and managers in the UK and internationally.

\subsection{Geomorphological context, advanced techniques and future directions}

The ERI scoring method was developed with the characteristics of Scottish rivers in mind, but should be directly applicable in similar environments. Scottish rivers are diverse, but their overall rates of lateral adjustment are low. The new ERI scoring system has not been assessed across a greater variety of river planform styles (such as multi-channel systems) or for rivers with significant vertical adjustment. In different environments, more extensive and detailed classifications may need to be applied (such as the Morph framework and the river styles framework; see Section 1), especially if the assessment of stability of longer reaches is of interest.

Geomorphological assessments increasingly implement a variety of new technologies for the quantification of river change over a range of scales. River bank stability can be directly measured using repeat high-resolution topographic surveys using terrestrial laser scanning (Williams et al., 2015), structure-from-motion photogrammetry (Tamminga et al., 2015), airborne Lidar (Jones et al., 2007) and satellite remote sensing (Syvitski et al., 2012). In addition, a number of analytical approaches for quantifying topographic change detection between surveys have been developed to include robust assessments of uncertainty (Wheaton et al., 2010; Williams, 2012). The deployment of these approaches to support asset stability assessments depends on the rate and timing of geomorphic change. The ERI method is one way to pre-screen sites to inform decisions about the need to deploy additional, costly surveying resources.

Arising from developments in data collection technologies and advances in communications and protocols such as the Internet of Things, the efficient extraction, filtering and interpretation of large amounts of real-time geomorphological data is a significant future challenge and opportunity. Simple frameworks, such as the one presented in this paper, can accept a range of data as input (e.g. the replacement of approximations of bank erosion risk with volumetric changes measured from repeat wearable laser scanning, or repeat Unmanned Aerial Vehicles (UAV)/Structure from Motion (SfM) surveys). Hence, the ERI can link the increasing complexity in data acquisition to derived information that is necessary for effective and scientifically informed decision making and asset management.

\section{Conclusions}

A new ERI is proposed to assess the exposure of above-ground river pipe crossings to bank erosion using only photographic data. Derivation of the ERI requires the collection of appropriate spatially distributed photographs collected during regular asset inspections, which can then be assessed by asset managers who may not have comprehensive fluvial geomorphological training. The ERI is supplemented by an assessment of DQ to calculate a final score (ERI*), which allows immediate identification of sites for which insufficient data exist to make a reliable risk assessment. The ERI was verified against independently identified medium- to high-risk cases using a sequence of tests and the following results were obtained.

- Initial testing targeting the effect of user bias revealed that the ERI was stable and differences between users mainly concerned DQ.

- The desk-based calculation of ERI overestimated the susceptibility to bank erosion when compared with field-based calculations performed by expert geomorphologists using the same classification.

- Desk-based ERI scores obtained for 188 sites by SW assessors and a UoG geomorphologist showed agreement for the majority of cases. The differences were unbiased and mainly occurred where there were DQ issues, indicating repeat site visits were needed.

SW has implemented the new scoring system based on the methods described in this paper. The scoring system could be applied by other owners of above-ground river pipeline crossings. The procedure used to develop and test the ERI is transferable to the development of other asset management and assessment protocols.

\section{Acknowledgements}

This project was funded through the UK Natural Environment Research Council's Environmental Risks to Infrastructure Innovation Programme (grant NE/P008984/1). SW provided 
access to their databases and support from several SW staff is gratefully acknowledged.

\section{REFERENCES}

Arnell NW, Halliday SJ, Battarbee RW, Skeffington RA and Wade AJ (2015) The implications of climate change for the water environment in England. Progress in Physical Geography 39(1): 93-120, https://doi.org/10.1177/0309133314560369.

Arneson LA, Zevenbergen LW, Lagasse PF and Clopper PE (2012)

Evaluating Scour at Bridges, 5th edn. Federal Highway

Administration, Washington, DC, USA, Hydraulic Engineering Circular 18, FHWA-HIF-12-003.

Barker L, Hannaford J, Muchan K, Turner S and Parry S (2016)

The winter 2015/2016 floods in the UK: a hydrological appraisal. Weather 71(12): 324-333, https://doi.orgdoi:/ $10.1002 /$ wea. 2822.

Beechie T and Imaki H (2014) Predicting natural channel patterns based on landscape and geomorphic controls in the Columbia River basin, USA. Water Resources Research 50(1): 39-57, https://doi.org/10.1002/2013WR013629.

Brierley GJ and Fryirs KA (2013) Geomorphology and River Management: Applications of the River Styles Framework. Wiley, Chichester, UK

Buffington JM and Montgomery DR (2013) Geomorphic classification of rivers. In Treatise on Geomorphology 9: Fluvial Geomorphology (Shroder J and Wohl E (eds)). Academic Press, San Diego, CA, USA, pp. 730-767.

Campos J, Jantunen E, Baglee D et al. (2017) Mobile information systems in maintenance engineering and asset management. Societal Studies 8(2):180-197.

Cabinet Office (2010) Sector Resilience Plan for Critical Infrastructure. Cabinet Office, London, UK.

Coleman SE and Melville BW (2001) Bridge-scour Screening Methodology for New Zealand Bridges. Transfund New Zealand, Wellington, New Zealand, Transfund New Zealand Research Report 196.

Connell BA (2012) GIS-Based Streambank Video Mapping to Determine Erosion Susceptible Areas. MSc thesis, University of Tennessee, Knoxville, TN, USA. See https://trace.tennessee.edu/utk_gradthes/ 1141/ (accessed 15/04/2019).

Darby SE and Thorne CR (1996) Development and testing of riverbank stability analysis. Journal of Hydraulic Engineering 122(8): 443-454.

Dorafshan S and Maguire M (2018) Bridge inspection: human performance, unmanned aerial systems and automation. Journal of Civil Structural Health Monitoring 8(3): 443-476, https://doi.org/ 10.1007/s13349-018-0285-4.

Emmanouilidis C, Liyanage JP and Jantunen E (2009) Mobile solutions for engineering asset and maintenance management. Journal of Quality in Maintenance Engineering 15(1): 92-105, https://doi.org/ $10.1108 / 13552510910943903$.

Garnaut R (2008) The Garnaut Climate Change Review. Cambridge University Press, Cambridge, UK.

Gaudreault V and Lemire P (2006) The Age of Public Infrastructure in Canada. Statistics Canada, Ottawa, Canada.

G/FLRPC (Genesee/Finger Lakes Regional Planning Council) (1998) Seneca Lake WMP: Chapter 7L-1; Sources of Pollution, Streambank Erosion. G/FLRPC, Rochester, NY, USA. See http://www.gflrpc. org/uploads/3/1/9/1/31916115/locallawsflwaterquality.pdf (accessed 15/04/2019).

Hall JW, Henriques LL, Hickford AJ et al. (2014) Assessing the long-term performance of cross-sectoral strategies for national infrastructure. Journal of Infrastructure Systems 20(3):
4014014, https://doi.org/10.1061/\%28ASCE\%29IS.1943-555X. 0000196.

Hall JW, Tran M, Hickford AJ and Nicholls RJ (eds) (2016) The Future of National Infrastructure: A System-of-Systems Approach. Cambridge University Press, Cambridge, UK.

Hoey TB, Smart DWJ, Pender G and Metcalfe N (1998) Engineering Methods for Scottish Gravel Bed Rivers. Scottish Natural Heritage, Inverness, UK. Scottish Natural Heritage Review No. 47.

ICE (Institution of Civil Engineers) (2009) The State of the Nation: Defending Critical Infrastructure. ICE, London, UK.

Johnson PA (2005) Preliminary assessment and rating of stream channel stability near bridges. Journal of Hydraulic Engineering 131(10): 845-852, https://doi.org/10.1061/(ASCE)0733-9429(2005) 131:10(845).

Johnson PA (2006) Assessing Stream Channel Stability at Bridges in Physiographic Regions. Office of Infrastructure Research and Development, Federal Highway Administration, Washington, DC, USA, USA, No. FHWA-HRT-05-072.

Jones AF, Brewer PA, Johnstone E and Macklin MG (2007) High-resolution interpretative geomorphological mapping of river valley environments using airborne LiDAR data. Earth Surface Processes and Landforms 32(10): 1574-1592, https://doi.org/ 10.1002/esp. 1505

Kim MK, Won JH, Cho SH and Park M (2013) Integrated assessment for route selection of river-crossing pipeline using structural and hydraulic approach. Structure and Infrastructure Engineering 9(9): 860-876, https://doi.org/10.1080/15732479.2011.627349.

Kirby A, Roca M, Kitchen A, Escarameia M and Chesterton O (2015) Manual on Scour at Bridges and Other Hydraulic Structures. CIRIA, London, UK, Publication C742.

Marsh T, Kirby C, Muchan K et al. (2016) The Winter Floods of 2015/ 2016 in the $U K-A$ Review. NERC Centre for Ecology \& Hydrology, Wallingford, UK. See http://nora.nerc.ac.uk/id/eprint/ 515303 (accessed 19/07/2019).

MDEQ (Michigan Department of Environmental Quality) (2001) Michigan Department of Environmental Quality, Streambank Erosion Inventory (SEI). MDEQ, Lansing, MI, USA. See https://www.michigan.gov/deq/0,4561,7-135-3308-266777-,00.html (accessed 15/04/2019).

Micheli ER and Kirchner JW (2002) Effects of wet meadow riparian vegetation on streambank erosion. 2. Measurements of vegetated bank strength and consequences for failure mechanics. Earth Surface Processes and Landforms 27(7): 687-697, https://doi.org/ 10.1002/esp. 340 .

Osman AM and Thorne CR (1988) Riverbank stability analysis I: Theory. Journal of Hydraulic Engineering 114(2): 134-150.

Perfect C, Addy S and Gilvear D (2013) The Scottish Rivers Handbook: $A$ Guide to the Physical Character of Scotland's Rivers. Centre of Expertise for Waters, Aberdeen, UK.

Pitt M (2008) Learning Lessons from the 2007 Floods (The Pitt Review). Cabinet Office, London, UK

Rosgen DL (2001a) A practical method of computing streambank erosion rate. Proceedings of the 7th Federal Interagency Sedimentation Conference, Reno, NV, USA, vol. 2, pp. 9-15.

Rosgen DL (2001b) A hierarchical river stability/watershedbased sediment assessment methodology. In Proceedings of the 7th Federal Interagency Sedimentation Conference, Reno, NV, USA.

Rosgen D and Silvey HL (1996) Applied River Morphology. Wildland Hydrology, Pagosa Springs, CO, USA

Sear D, Newson M, Hill C, Old J and Branson J (2009) A method for applying fluvial geomorphology in support of catchment-scale river restoration planning. Aquatic Conservation: Marine and Freshwater Ecosystems 19(5): 506-519, https://doi.org/ 10.1002/aqc. 1022 . 
Seelbach PW (1997) Overview of the Michigan Rivers Inventory (MRI) Project. Michigan Department of Natural Resources, Lansing, MI, USA. See https://www.michigan.gov/deq/0,4561,7-135-3308266777-,00.html (accessed 15/04/2019).

Shuker LJ, Gurnell AM, Wharton G et al. (2017) MoRPh: a citizen science tool for monitoring and appraising physical habitat changes in rivers. Water and Environment Journal 31(3): 418-424, https://doi.org/10.1111/wej.12259.

Simon A, Doyle M, Kondolf M et al. (2007) Critical evaluation of how the Rosgen classification and associated "natural channel design" methods fail to integrate and quantify fluvial processes and channel response 1. Journal of the American Water Resources Association 43(5): 1117-1131, https://doi.org/10.1111/j.1752-1688. 2007.00091.x.

Sonnenberg A (2012) Australian bridge inspection processes. Proceedings of the Australian Small Bridges Conference, 5th, Surfers Paradise, Queensland, Australia.

SW (Scottish Water) (2018) Shaping the Future of Your Water and Waste Water Services: Draft Strategic Projections. SW, Dunfermline, UK. See https://www.yourwater.scot/static/Shaping-the-futureconsultation-document-latest.pdf (accessed 15/04/2019).

Syvitski JPM, Overeem I, Brakenridge GR and Hannon M (2012) Floods, floodplains, delta plains - a satellite imaging approach. Sedimentary Geology 267-268: 1-14, https://doi.org/10.1016/ j.sedgeo.2012.05.014.

Tamminga A, Hugenholtz C, Eaton B and Lapointe M (2015) Hyperspatial remote sensing of channel reach morphology and hydraulic fish habitat using an unmanned aerial vehicle (UAV): a first assessment in the context of river research and management. River Research and Applications 31(3): 379-391, https://doi.org/10.1002/rra.2743.

Thompson V, Dunstone NJ, Scaife AA et al. (2017) High risk of unprecedented UK rainfall in the current climate. Nature
Communications 8(1): 107, https://doi.org/10.1038/s41467-01700275-3.

Vaghefi K, Oats RC, Harris DK et al. (2012) Evaluation of commercially available remote sensors for highway bridge condition assessment. Journal of Bridge Engineering 17(6): 886-895, https://doi.org/ 10.1061/(ASCE)BE.1943-5592.0000303.

Van Leeuwen Z and Lamb R (2014) Flood and Scour Related Failure Incidents at Railway Assets Between 1846 and 2013. JBA Trust, Skipton, UK, Project W13-4224.

WDNR (Wisconsin Department of Natural Resources) (2010a) Wisconsin Division of Natural Resources, Bank Erosion Potential Index (BEPI). WDNR, Madison, WI, USA. See https://dnr.wi.gov/topic/waterways/documents/PermitDocs/ GPs/GP-IntegratedBankTreatmentStreams.pdf (accessed $15 / 04 / 2019)$.

WDNR (2010b) Streambank Erosion Control. WDNR, Madison, WI, USA, Wisconsin Administrative Code NR 328.38.

Wheaton JM, Brasington J, Darby SE and Sear DA (2010) Accounting for uncertainty in DEMs from repeat topographic surveys: improved sediment budgets. Earth Surface Processes and Landforms 35(2): 136-156, https://doi.org/10.1002/esp.1886.

Williams RD (2012) Section 3.2:DEMs of Difference. In Geomorphological Techniques (Online Edition) (Cook SJ, Clarke LE and Nield JM (eds)). British Society for Geomorphology, London, UK. See https://www.geomorphology. org.uk/geomorph_techniques (accessed 30/7/2019).

Williams RD, Rennie CD, Brasington J, Hicks DM and Vericat D (2015) Linking the spatial distribution of bed load transport to morphological change during high-flow events in a shallow braided river. Journal of Geophysical Research: Earth Surface 120(3): 604-622, https://doi.org/10.1002/2014JF003346.

Xu G and Xu Y (2016) GPS: Theory, Algorithms and Applications, 3rd edn. Springer, Berlin, Germany.

\section{How can you contribute?}

To discuss this paper, please email up to 500 words to the editor at journals@ice.org.uk. Your contribution will be forwarded to the author(s) for a reply and, if considered appropriate by the editorial board, it will be published as discussion in a future issue of the journal.

Proceedings journals rely entirely on contributions from the civil engineering profession (and allied disciplines). Information about how to submit your paper online is available at www.icevirtuallibrary.com/page/authors, where you will also find detailed author guidelines. 